\title{
Maxillary Canine with Two Root Canals
}

\author{
Subbarayudu Alapati ${ }^{a}$ Essam I. Zaatar ${ }^{a}$ Maddi Shyama $^{\mathrm{b}}$ Nohoud Al-Zuhair $^{\mathrm{c}}$ \\ ${ }^{a}$ Bneid Al-Gar Dental Centre, Ministry of Health, ${ }^{b}$ National School Oral Health Program, Ministry of Health, and \\ ${ }^{c}$ Speciality Centre for Advancement of Dental Services, Kuwait
}

\section{Key Words}

Endodontics $\cdot$ Maxillary canine $\cdot$ Two canals

\begin{abstract}
Objective and Importance: To report a case of endodontic retreatment of a maxillary right canine in which an extra canal was located and successfully treated. Clinical Presentation and Intervention: A 35-year-old Asian male reported with pain and lingering discomfort in relation to his maxillary right canine after the conventional root canal therapy. Radiographic examination revealed the presence of another undetected and untreated root canal. Therefore, endodontic retreatment was performed and the patient reported complete relief of pain and found to be asymptomatic after a 3-month, 6-month and 1 -year recall period. Conclusion: For successful endodontic therapy, the clinician should be aware of the variations in the root canal morphology. The science of extra canal is important in endodontics as failure to locate and treat an extra canal(s) is one of the common causes for failure of root canal treatments.
\end{abstract}

Copyright (C) 2006 S. Karger AG, Basel

\section{Introduction}

Vertucci [1] classified the root canal configurations of human permanent teeth into various types ranging from single to three separate and distinct canals. Research into morphology of pulp has shown a wide variety of shapes and the occurrence of two or even three canals in a single root. There is a high incidence of fins which run longitudinally within the walls of the canal and a network of communication between canals lying within the same root attributing to multiple root canals in single root teeth. Root canal morphology and the prevalence of root canals in various teeth have been investigated by numerous authors [1-4].

In mandibular anterior teeth, the prevalence of two or three root canals has been reported to be as low as $1 \%$ and as high as $43 \%[2,4]$. Mandibular canines are recognized as having one root and one root canal in the majority of cases. Investigators have reported on the anatomical variations associated with mandibular canines and that $15 \%$ of mandibular canines presented with two canals with one or two foramina $[1,2,4]$. A rare case of a root canal retreatment in a mandibular canine with two roots and three canals has been described [5]. Three canals and two foramina in a mandibular canine were recognized [6]. Mandibular canines with two roots and two canals were described [7]. All these cases are suggested to be the result of the abnormal development of the tooth and the root.

Maxillary canines are considered to be single-rooted, single-canaled teeth and two root canals in a permanent maxillary canine is a rare condition [1-3]. Multiple canals and multiple roots of maxillary anterior teeth with or without any developmental anomalies have been reported [1-3].

\begin{tabular}{ll}
\hline KARGER & ( ) 2006 S. Karger AG, Basel \\
Fax +4161306 1234 34 -7571/06/0151-0074\$23.50/0 \\
$\begin{array}{l}\text { E-Mail karger@karger.ch } \\
\text { www.karger.com }\end{array}$ & $\begin{array}{l}\text { Accessible online at: } \\
\text { www.karger.com/mpp }\end{array}$
\end{tabular}

Dr. Subbarayudu Alapati PO Box 1952 
1

Fig. 1. Preoperative radiograph showing the missed canal.

Fig. 2. Missed canal located palatally to the previously filled canal in the same root.

Fig. 3. Working length radiograph showing type II canal configuration.

Fig. 4. Postoperative radiograph showing the two canals obturated properly.

3

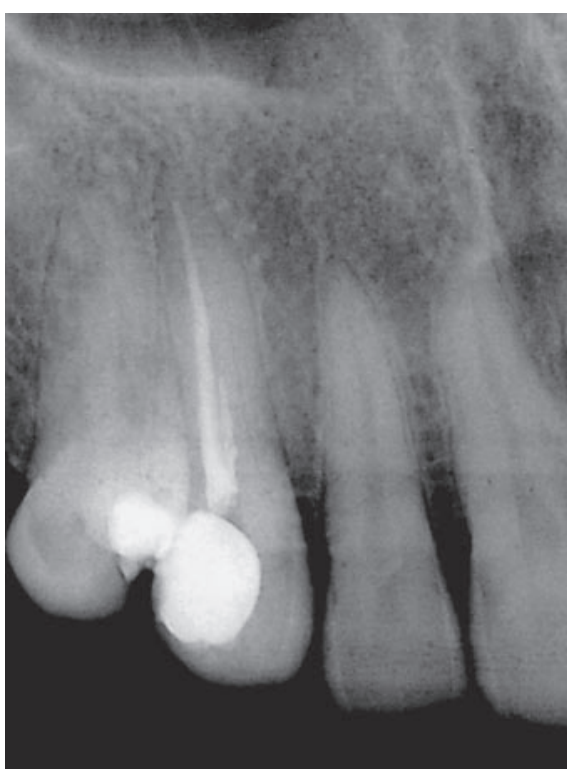

2
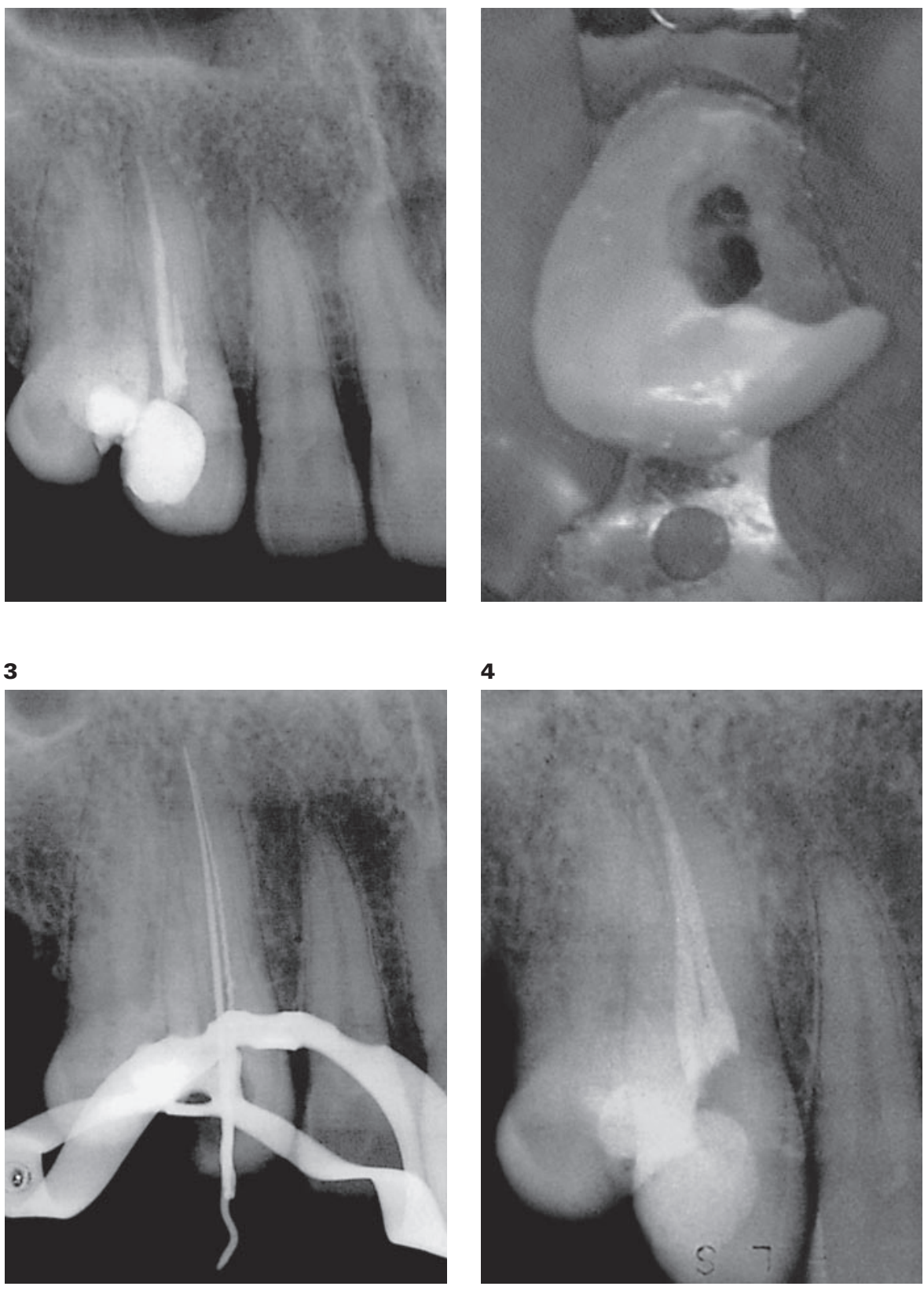

Maxillary central and lateral incisors have single canals $[1,2]$. However, aberrations of maxillary anterior teeth have been reported in the literature [8-11], involving two roots and two canals in maxillary central incisors [8], two roots and two root canals in maxillary lateral incisor [9], maxillary lateral incisor with two root canals [10] and lateral incisor with three root canals [11]. In this report, we describe a case of multiple canals in a single rooted maxillary canine which is extremely rare.

\section{Case Report}

A 35-year-old Asian male reported with pain and lingering discomfort in relation to his maxillary right canine after the conventional root canal therapy. Radiographic examination revealed the presence of another undetected and untreated root canal (fig. 1). Therefore, retreatment was necessary and rubber dam was placed and the access established. The previous gutta percha root canal filling was removed and the missed canal identified. It was located palatally to the previously filled canal in the same root (fig. 2). The root canal configuration was of two canals leaving the floor of the pulp chamber, converging into one canal, to exit at a single apical 
foramen. Working length was determined using files \#20 and \#15, respectively (fig. 3). It was found that the palatal canal joined the buccal canal just in the apical third of the root (type II configuration of Vertucci classification of root canal configurations). The two canals were cleaned, shaped, filled with calcium hydroxide paste and the tooth was temporized using cavit. The patient reported complete relief of pain after one week, when the canals were obturated with lateral condensation technique using gutta percha and AH-26 sealer (fig. 4).

The patient was recalled after a 3-month, 6-month and 1-year period and found to be asymptomatic.

\section{Discussion}

Morphological features of the tooth may adversely affect endodontic procedures. A thorough knowledge of both the external and internal anatomy of teeth is an important aspect of root canal treatment and is essential for the highest possible chance of success. Failure to locate and treat an extra canal/s is one of the most common causes of failures of root canal treatment. In the teeth particularly with additional root canals or anatomical variations, root canals are often left untreated because the clinicians fail to identify their existence. Most of the extra canals can be found if the clinician is alert to the clues that suggest their presence.

A thorough and careful radiographic evaluation and endodontic exploration may lead to identification or suspicion of additional canals. Radiographs from different angles, some with a file in place may be helpful in finding and locating extra canals. The relationship of the two canal orifices to each other is also significant, as the closer the orifices are to each other, the greater the chances that the two canals join at some point within the body of the root [1-3]. In finding extra canals, it is important to identify periodontal ligament space that often projects on the tooth and may resemble a canal. In this case, examination of the pulpal floor and radiographs taken with a file confirmed the existence of the extra canal.

Although the prevalence of the root canal anomalies is low, they should be detected by careful examination. Detailed knowledge of the anatomical variations in the root canal and awareness of their configuration is essential and the clinicians should never assume that root canal systems are simple because endodontic success is related to a thorough debridement of the total root canal system. In the teeth particularly with additional root canals or anatomic variations, root canals are often left untreated because the clinicians fail to identify their existence.

\section{Conclusion}

This report shows a case of the presence of a second canal in a single-rooted maxillary canine. Such an anatomic finding has not been cited earlier. This case report is given to increase the awareness of clinicians on aberrations in tooth morphology of anterior teeth and to show that special care is required to detect possible extra canals.

\section{References}

1 Vertucci F: Root canal anatomy of the human permanent teeth. Oral Surg Oral Med Oral Pathol 1984;58:589-599.

2 Pineda F, Kuttler Y: Mesiodistal and buccolingual roentgenographic investigation of 7,275 root canals. Oral Surg Oral Med Oral Pathol 1972;33:101-110.

- 3 Caliskan MK, Pehlivan Y, Sepetcioğlu F, Türkun M, Tüncer SS: Root canal morphology of human permanent teeth in a Turkish population. J Endod 1995;21;200-204.
4 Vertucci FJ: Root canal anatomy of the mandibular anterior teeth. J Am Dent Assoc 1974; 89:369-371.

5 Heling I, Gottlieb-Dadon I, Chandler N: Mandibular canine with two roots and three root canals. Endod Dent Traumatol 1995;11:301302.

-6 Orguneser A, Kartal N: Three canals and two foramina in a mandibular canine. J Endod 1998;24:444-445.

7 D'Arcangelo C, Varvara G, De Fazio P: Root canal treatment in mandibular canines with two roots: a report of two cases. Int Endod J 2001;34:331-334.
8 Sinai IH, Lustbader S: A dual-rooted maxillary central incisor. J Endod 1984; 10:105-106.

-9 Zillich R, Ash J, Corcoran J: Maxillary lateral incisor with two roots and dens formation: a case report. J Endod 1983;9:143-144.

10 Thompson B, Portell F, Hartwell G: Two root canals in a maxillary lateral incisor. J Endod 1985;11:353-355.

11 Walvekar SV, Behbehani JM: Three root canals and dens formation in a maxillary lateral incisor: a case report. J Endod 1997;23:185186. 